International Journal of Engineering \& Technology, $7(3.29)(2018) 21-25$
SPC
International Journal of Engineering \& Technology
Website: www.sciencepubco.com/index.php/IJET
Research paper

\title{
Hydrodynamic studies comparison by simulation with experimental results of reverse fluidized bed
}

\author{
H. Upender ${ }^{1}$ *, L. Pavan Kumar ${ }^{1}$, Dr. K. Anand Kishore ${ }^{1}$ \\ ${ }^{1}$ Department of chemical engineering, NIT Warangal, Telangana, India \\ *Corresponding author E-mail: Upender07053@gmail.com
}

\begin{abstract}
In present days we are much believed computer aided (simulation) results much more than our experimental results even though time consumption, low-cost processes and we can get the efficient results when compare to experimental results. In this task, I compared my experimental results with simulation results (Ansys fluent version 17.2) in the solid liquid reverse fluidized bed system. In this, I did this comparison using Gidaspow drag model and remaining parameters were same the particle diameter was changed. I found that the hydrodynamic behavior by experimentally and by simulation those were bed height profile, pressure drop profile and Voidage profile by changing the velocity profile
\end{abstract}

Keywords: Reverse Fluidization; Simulation; Hydrodynamics.

\section{Introduction}

Fluidized bed apparatus have been utilized in numerous areas of technology and had to do in botanical healing of commercial and civic waste product (Nicolle et al., 2000). The fluidized bed application entrusted a strings of assets contrasted to other sart of anaerobic systems (Diez-Blanco et al., 1995), those are way up biological loading rates and brief hydraulic holding seasons. Hence, a numeral of layout variations have been tried or followed in order to enhance the staging of the coordination. These apparatus inspected the cubicles' immobilisation on dead solids to expand the accessible region intended biofilm growth. The bed equipped a quiet conditions that limited effort of elevated fuel attentiveness inside the setup and a lengthy mean cell duration time short of hampering disputes (Shieh and Hsu, 1996). The downward flow bed or reverse fluidized bed apparatus has been illustrated for approach in the anaeroboic treatment about effluent (Garcia-Calderon et al., 1998a). In their delineation, of reverse flow fluidization, solids with a specific gravity slighter than the fluid were in downward by

A concurrent motion of fluid. This journal illustrates the advantage of the flow (or reverse) fluidization application for the anaerobic absorption of red vino distillery effluent and shows good out-turns differentiated to other apparatus (Gangagni Rao et al., 2005). . The environment of the media utilized for biofilm fondness has kept a substantial issue on the apparatus potential. In this observation the bearer substance, exist perlite, an enlarged extrusive cliff. Perlite was an fascinating bearer when differentiated to others like cork, polypropylene (Garcia-Calderon et al., 1998a). Elaborate operations consist of fluidized bed application with immobilized cubicles. Anticipated to the huge specific area of espousal solids convenient for fuel holding, this application assets in high-strength waste-water treatment by reduced area and shorter hydrodynamic holding time. Another application of reverse fluidization is the less energy essential with regard to conventional fluidization, by using support substances with a lower thickness than effluent (GarciaCaldero'n et al., 1998). This application has been mostly pre-owned by aerophillic schemes. Only a few suits of anaerobic reverse fluidized bed apparatus (IFBR) have been investigated (Spiess et al., 1991; Gonza'lez et al., 1992; Meraz et al., 1996; Garcia-Bernet et al., 1998). In malignity of the uses included earlier, there exist some key constants that limit popular advantages of this study like as: support matter choosing, installation of apparatus governing trims, and irreparable biofilm forming in a quick spell season. Span of biofilm establishment from [2] to [9] months (Lauwers et al., 1990). Many innovative researches were accomplished till today to look at the hydrodraulics of reverse fluidization. We can gain knowledge regarding the design of the stream in a fluidized bed in empirical investigations. Even though these approaches have shown to be of considerable concern, there are also restrictions and a complete canvas of the stream paddock is sometimes harsh to gain to avoid these problems computerized Computational Fluid Dynamics, oftentimes termed as CFD, is the approach designed model fluid stream utilizing a simulation. Till today, no CFD evolution has been done on reverse apparatus. Therefore, this one is essential to do a reproduction to take in the conventional flow activity much undoubtedly. A major benefit of CFD is extremely effective, subtle, effective modeling approach with dominant visualization potentials, and one can assess the entertainment of broad assortment of setup geographies on the processing system without the period, cost, and interruption required to lead to genuine changes onsite.

\section{Methods}

\subsection{Natural properties of particles}

LDPE (Low thickness polyethylene) was a fascinating bearer when contrasted with others as plug, polypropylene (Garcia-Calderon et al., 1998a). The watched physical properties of LDPE solids were utilized as a part of this test as takes after: The determined natural assets of LDPE solids were used in this test as attends: Density: $835 \mathrm{~kg} / \mathrm{m} 3$, Diameters were $0.0025 \mathrm{~m}, 0.0033$ and $0.0042 \mathrm{~m}$ and 
shape of solids was spherical, and water is used as fluid media and density was $1000 \mathrm{~kg} / \mathrm{m} 3$

\subsection{Experimental set-up}

The reverse fluidized bed setup comprised concerning section accompanied by an aggregate stature about $0.7 \mathrm{~m}$ and $0.05 \mathrm{~m}$ in measurement. The stream merchant also the fluid discharge has been put at the eradicable top passing over the base segment. The inverse fluidized bed apparatus consisted of column with a complete height about $0.7 \mathrm{~m}$ and $0.05 \mathrm{~m}$ in breadth. The flow supplier and the fluid discharge section have been kept at the dismissible cap containing at the bottom section. The water inlet from top of the column was connected to liquid Rota meter. In the reactor distributors ware connected at bottom and top of the column because these were used to pump the water uniformly throughout processes and its acts as protect the escape of the particles, pressure tapping were mounted on the top, bottom and center of the column and those were connected to u-tube manometers to measure the pressure drop which was filled with carbon tetra chloride (CCL4).

\subsection{CFD model setup}

The experimental setup was designed in CFD with reactor size $(0.7 \mathrm{mX} 0.05 \mathrm{~m})$, and coarse grid $(50 \times 600)$ where the cells were more than 10 times the particle diameter. Gidaspow drag model was used with first order upwind scheme was used. The time step size is 0.01 with number of time step size is 20 and total hydrodynamics were calculated within in $0-10 \mathrm{sec}$. The velocity of water boundary condition were $(0.014-0.09) \mathrm{m} / \mathrm{s}$ used, Initial volume fraction of solids were adapted in the region was 0.7 (initial bed height $=0.05 \mathrm{~m}$ )

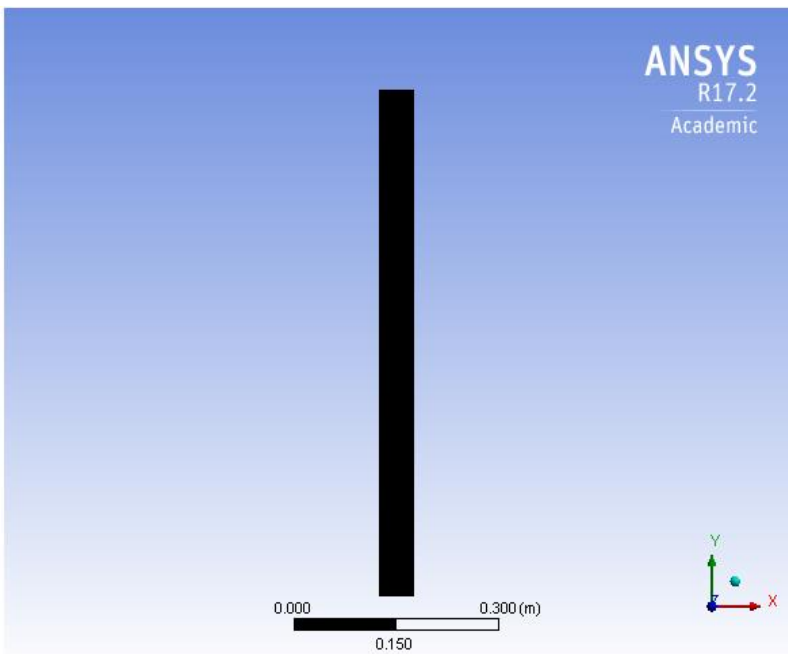

Fig. 1: Schematic Mesh of Inverse Fluidized Bed.

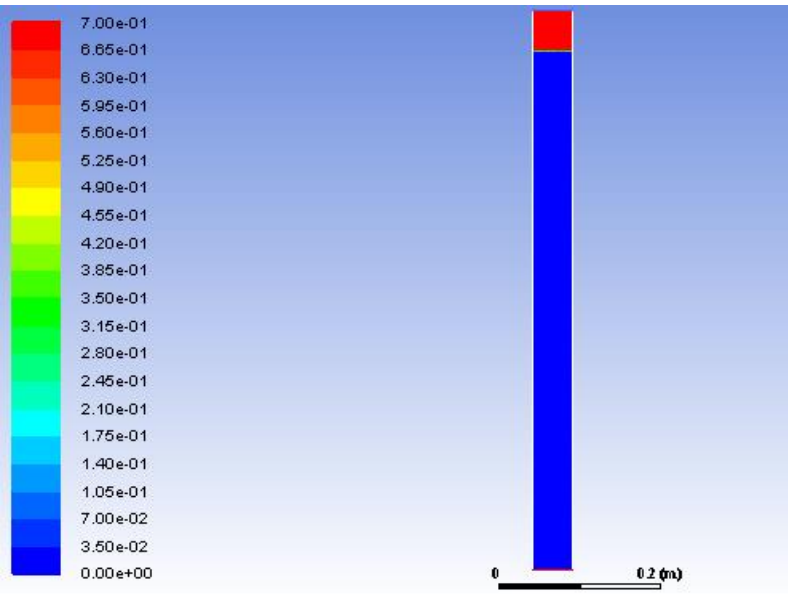

Fig.2: Computational Domain with the Boundary Condition.
Parameters used in simulations.

\begin{tabular}{lll}
\hline Parameters & Numerical value & Units \\
\hline Reactor size & $0.05^{*} 0.7$ & $\mathrm{~m}$ \\
Grid number & $50^{*} 600$ & - \\
Convergence criteria & $10^{\wedge}-3$ & $\mathrm{~s}$ \\
Maximum iterations & 1000 & $\mathrm{~s}$ \\
Time step size & 0.01 & $\mathrm{~s}$ \\
Discretization method & First order upwind scheme & - \\
Model precision & Double & - \\
Initial volume fraction(solid) & 0.7 & - \\
$\mathrm{e}_{\mathrm{sw}}$ & 0.9 & - \\
Operating pressure & $1.013 \times 105$ & $\mathrm{~Pa}$ \\
Granular viscosity & Gidaspow $(1994)$ & $\mathrm{Pas}$ \\
Granular bulk viscosity & Lun et al. $(1984)$ & $\mathrm{Pas}$ \\
Solid pressure & Lun et al. $(1984)$ & $\mathrm{Pa}$ \\
Radial distribution & Lun et al. $(1984)$ & - \\
Drag model & Gidaspow & - \\
$\mathrm{e}_{\mathrm{ss}}$ & 0.9 & - \\
$\Phi$ (specularity coefficient) & No slip condition & - \\
Velocity(liquid) & $(0.0014-0.9)$ & $\mathrm{m} / \mathrm{s}$ \\
Particle diameter & $0.0022,0.0033,0.0 .0042$ & $\mathrm{~m}$ \\
Density of particle $(\rho s)$ & 835 & $\mathrm{Kg} / \mathrm{m} 3$ \\
Density of water $(\rho \mathrm{s})$ & 1000 & $\mathrm{Kg} / \mathrm{m} 3$ \\
Initial bed height & 0.05 & $\mathrm{~m}$ \\
\hline
\end{tabular}

Modeling equations in fluent CFD code

$\partial / \partial t\left(\alpha_{q} \rho_{q}\right)+\nabla \cdot\left(\alpha_{q} \rho_{q} v_{q} \rightarrow\right)=0$ Continuity equations

$\partial / \partial t\left(\alpha_{l} \rho_{l} \overrightarrow{v_{l}}\right)+\nabla \cdot\left(\alpha_{l} \rho_{l} \overrightarrow{v_{l}} \overrightarrow{v_{l}}\right)=-\alpha_{l} \nabla p+\nabla \cdot \overline{\overline{\tau_{l}}}+\alpha_{l} \rho_{l} g+K_{s l}($ $\left.\overrightarrow{v_{s}}-\overrightarrow{v_{l}}\right)$ Momentum equation

$\partial / \partial t\left(\alpha_{S} \rho_{S} \overrightarrow{v_{S}}\right)+\nabla \cdot\left(\alpha_{S} \rho_{S} \overrightarrow{v_{S}} \overrightarrow{v_{S}}\right)=-\alpha_{l} \nabla p-\nabla \cdot \overline{\overline{\tau_{S}}}+\alpha_{S} \rho_{S} g+K_{S l}($ $\left.\overrightarrow{v_{l}}-\overrightarrow{v_{s}}\right)$

$\overline{\overline{\tau_{l}}}=\alpha_{l} \mu_{l}\left(\nabla \overrightarrow{v_{l}}+\nabla{\overrightarrow{v_{l}}}^{T}\right)-\frac{2 \alpha_{l} \mu_{l}}{3}\left(\nabla \cdot \overrightarrow{v_{l}}\right) \overline{\bar{I}}$

$K_{s l}=\frac{3}{4} C_{D} \frac{\alpha_{s} \alpha_{l} \rho_{l}\left(\overrightarrow{v_{s}}-\overrightarrow{v_{l}}\right)}{d_{s}} \alpha_{l}{ }^{-2.65}$ For $\alpha_{l}>0.8$ Gidaspow, model

$K_{s l}=150 \frac{\alpha_{s}\left(1-\alpha_{l}\right) \mu_{l}}{\alpha_{l} d^{2}{ }_{s}}+1.75 \alpha_{s} \rho_{l} \frac{\left(\overrightarrow{v_{s}}-\overrightarrow{v_{l}}\right)}{d_{s}}$ For $\alpha_{l} \leq 0.8$

$C_{D}=\frac{24}{\varepsilon_{l} R e_{s}}\left[1+0.15\left(\alpha_{l} R e_{s}\right)^{0.687}\right]$ For $R e_{s} \leq 10000.44$ For

$R e_{S}>1000$

$R e_{s}=\rho_{l} d_{s} \frac{\left|\overrightarrow{v_{s}}-\overrightarrow{v_{l}}\right|}{\mu_{l}}$

Where Re is the Reynolds number and $C_{D}$ is the drag coefficient

$P^{*}{ }_{S}=\alpha_{S} \rho_{S} \Theta_{S}+2 \rho_{S} g_{o, S S} \alpha_{S}^{2} \Theta_{S}\left(1+e_{S S}\right)$ Solid pressure

$\lambda_{s}=\frac{4}{3} \alpha_{s} \rho_{S} d_{s} g_{o, s S}\left(1+e_{S S}\right)\left(\frac{\Theta_{s}}{\Pi}\right)^{1 / 2}$ Bulk viscosity

$g_{o, s s}=\left[1-\left(\frac{\alpha_{s}}{\alpha_{s, \max }}\right)^{\frac{1}{3}}\right]^{-1}$ Ding and Gidaspow

\section{Results and discussion}

When I getting the simulation results by comparing the simulation results with my experimental data I found that the following

a) Bed height profiles

1) Diameter:0.0022m 


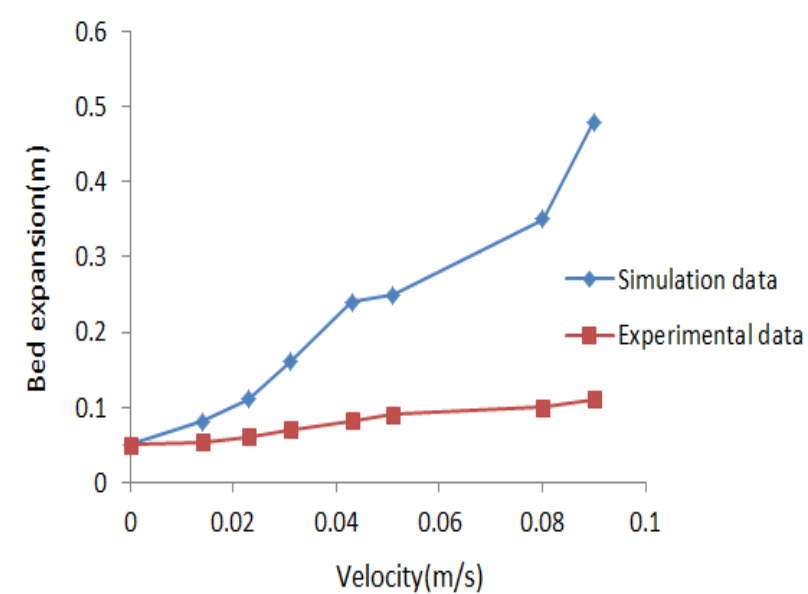

Fig 3: Comparison of Bed Height Profiles By Simulation with Experimental Data at Dia: $0.002 \mathrm{~m}$.

2) Diameter: $0.0033 \mathrm{~m}$

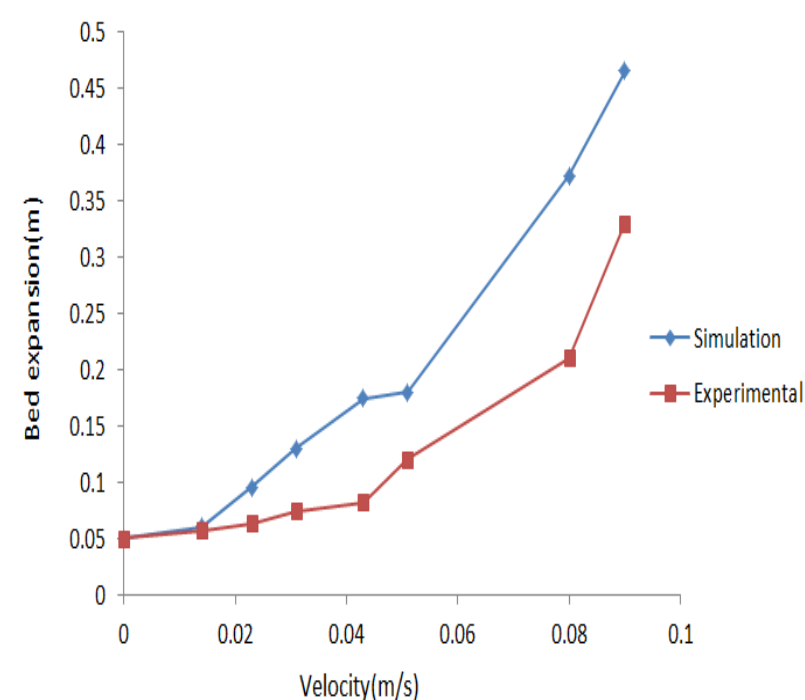

Fig. 4: Comparison of Bed Height Profiles by Simulation with Experimental Data at Dia: $0.0033 \mathrm{~m}$

3) Diameter: $0.0042 \mathrm{~m}$

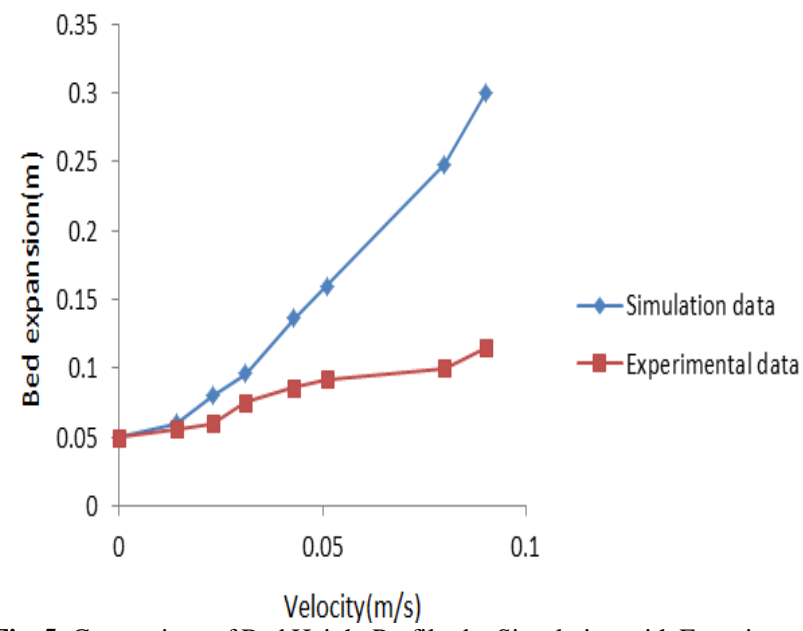

Fig. 5: Comparison of Bed Height Profiles by Simulation with Experimental Data at Dia: $0.0042 \mathrm{~m}$

From figs 3, 4, 5 I found that different diameter of particles the bed was expanded for different velocities for large diameter of particles the bed expansion profiles were high. The bed was expanded the fluidization velocity was reached the minimum fluidization velocity at that time the fluidization was termed as onset fluidization. The bed expansion profiles by simulation and by experimental data trend was almost same but bed expansion by simulation high than experimental because in the processes experiment there was some water leakages and for uniform flow uses distributor.

b) Bed Voidage profiles

1) Diameter:0.0022m

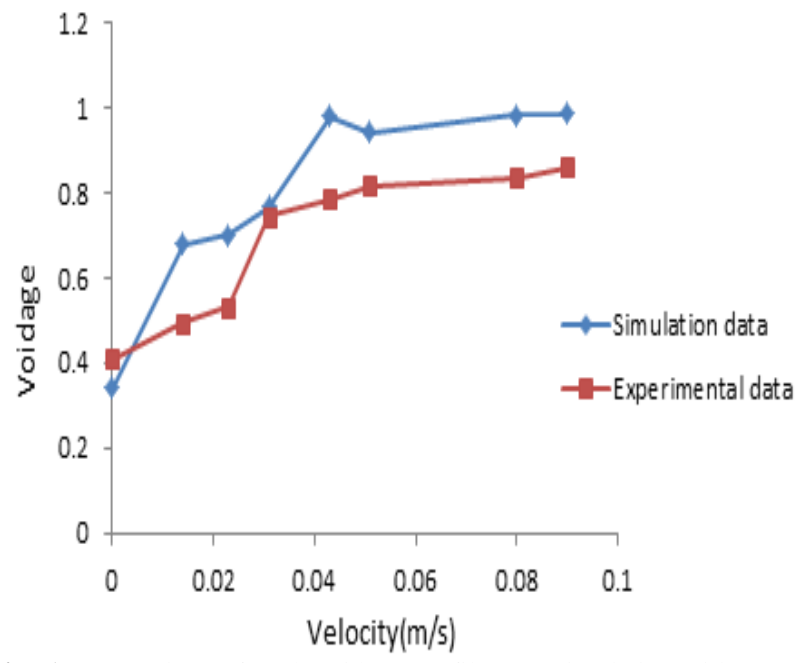

Fig. 6: Comparison of Bed Voidage Profiles By Simulation with Experimental Data at Dia: $0.0022 \mathrm{~m}$.

2) Diameter:0.0033m

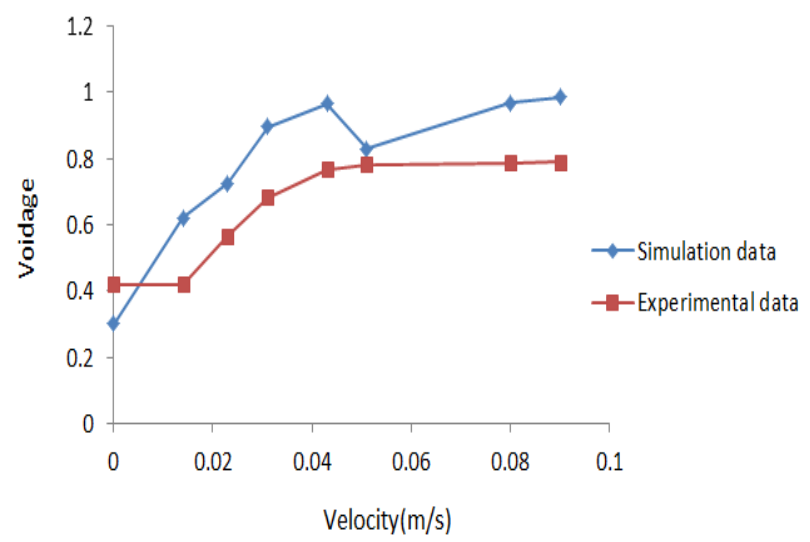

Fig. 7: Comparison of Bed Voidage Profiles by Simulation with Experimental Data at Dia: $0.0033 \mathrm{~m}$

3) Diameter: $0.0042 \mathrm{~m}$

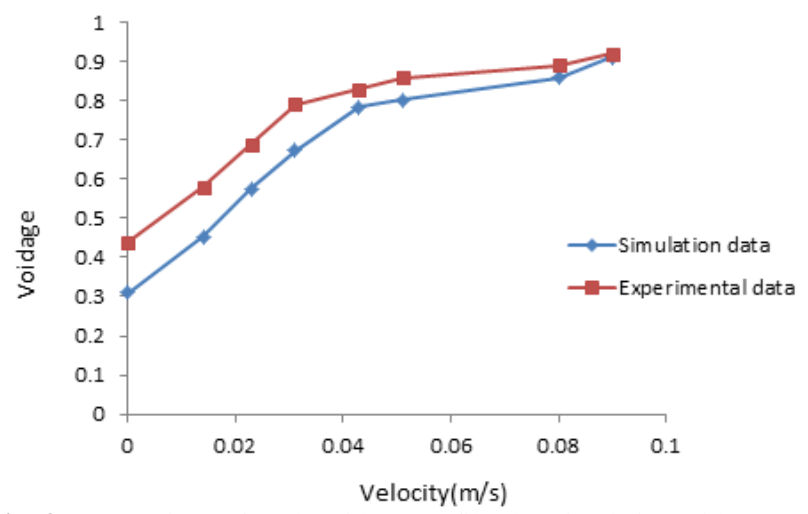

Fig. 8: Comparison of Bed Voidage Profiles by Simulation with Experimental Data at Dia: $0.0042 \mathrm{~m}$.

From figs 5, 6, 7 the void space between the particles was increased by increasing the fluid velocities from the experimental and simulation the trend was same

c) Pressure drop profile
1) Diameter: $0.0022 \mathrm{~m}$ 


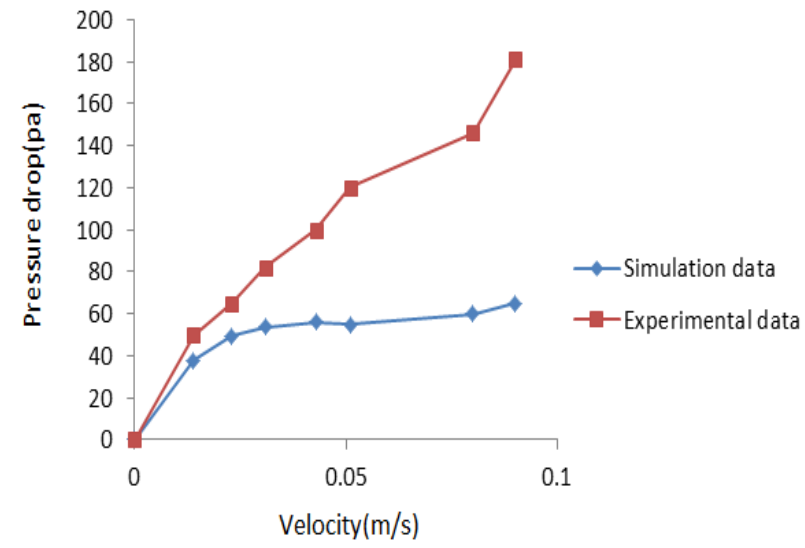

Fig. 9: Comparison of Bed Pressure Drop Profiles By Simulation with Experimental Data at Dia: $0.0022 \mathrm{~m}$.

2) Diameter: $0.0033 \mathrm{~m}$

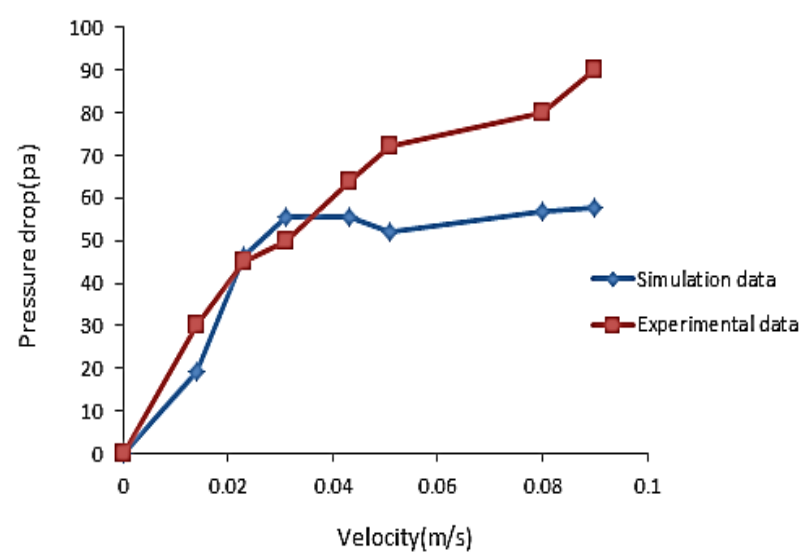

Fig. 10: Comparison of Bed Pressure Drop Profiles by Simulation with Experimental Data at Dia: $0.0033 \mathrm{~m}$.

3) Diameter: $0.0033 \mathrm{~m}$

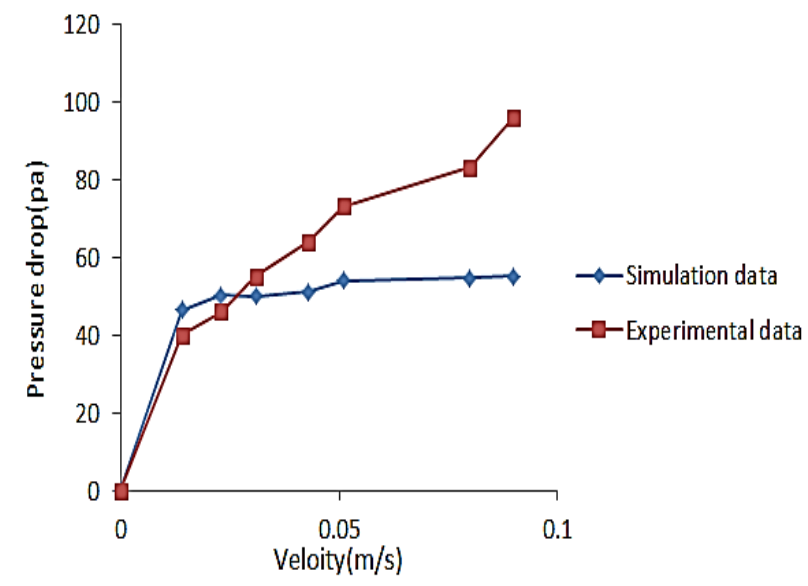

Fig. 11: Comparison of Bed Pressure Drop Profiles by Simulation with Experimental Data at Dia: $0.0042 \mathrm{~m}$.

From the graphs 9, 10, 11 I observed that the pressure drop was increased with increasing the velocities in both simulation and experimental. In Experimental the pressure drop was increased continuously but in simulation pressure drop increased up to one point and then constantly increased due to this in experimental setup there was a fluid leakage

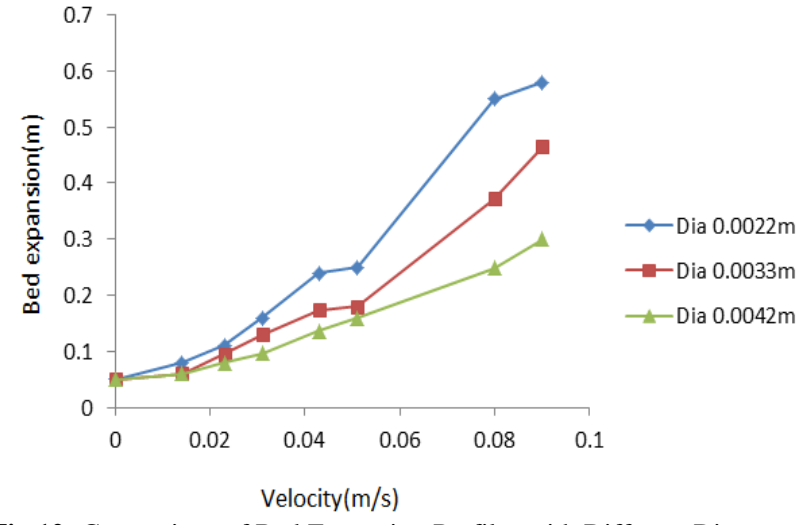

Fig 12: Comparison of Bed Expansion Profiles with Different Diameter of Particles by Simulation with Same Velocities

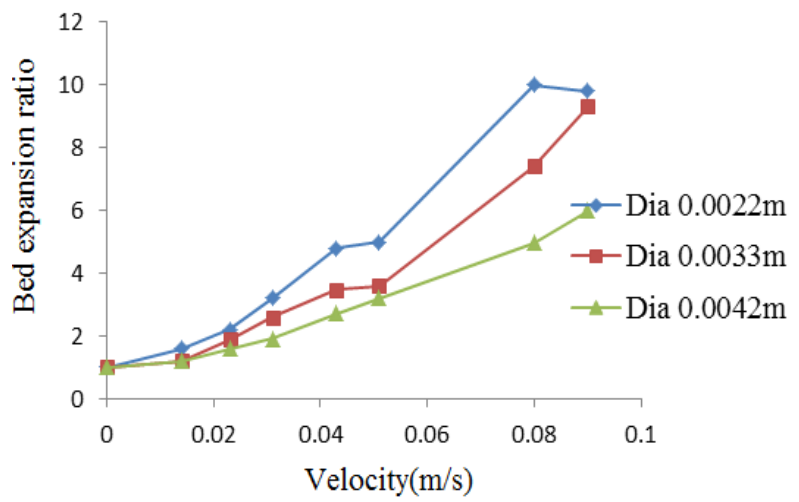

Fig 13: Comparison of Bed Expansion Ratio Profiles with Different Diameter of Particles by Simulation with Same Velocities.

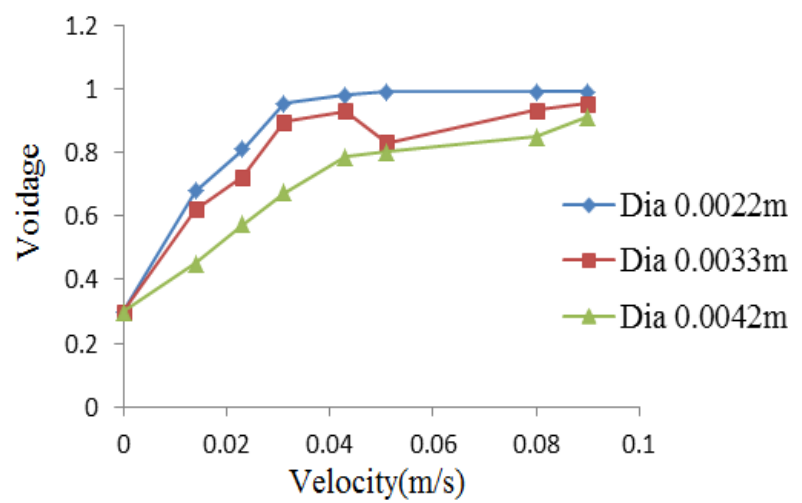

Fig 14: Comparison of Bed Voidage Profiles with Different Diameter of Particles by Simulation with Same Velocities.
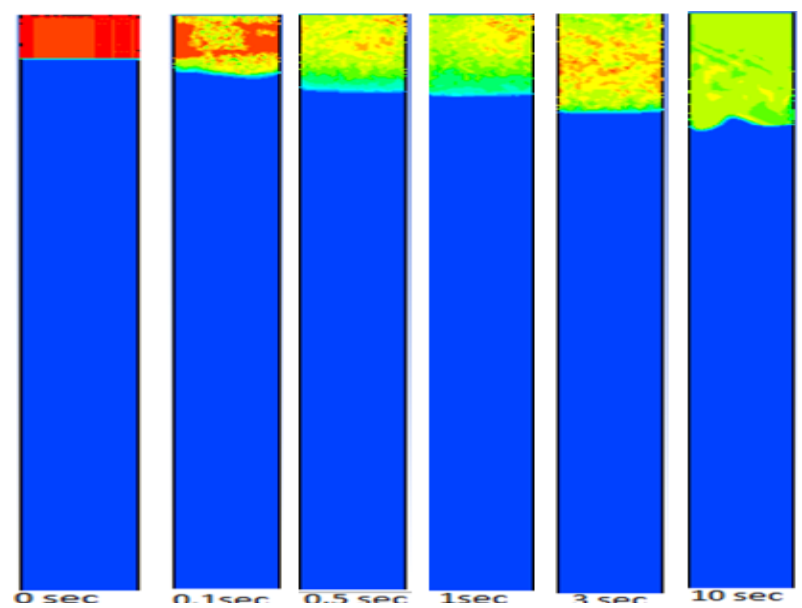

Fig 14: Comparison Bed Expansion Profiles of Inverse Fluidized Bed Reactor with Respect to Time(S). 


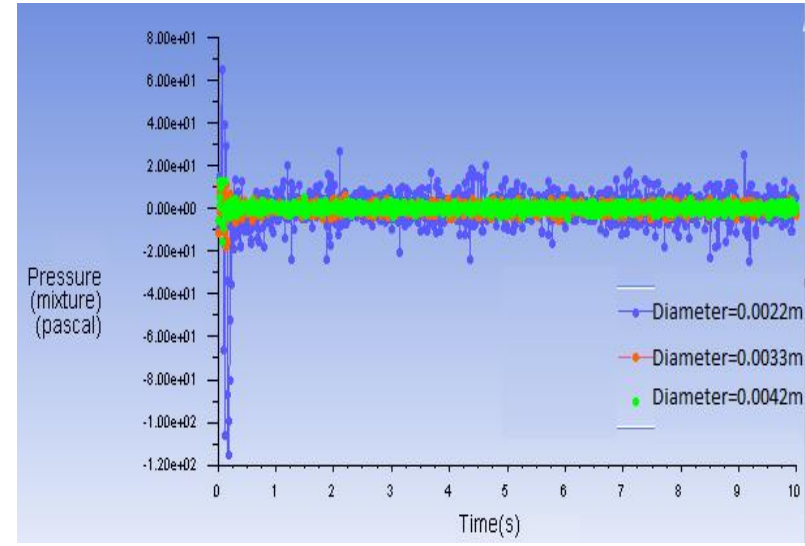

Fig. 15: Comparison of Bed Pressure Drop Profiles with Different Diameter of Particles with Time by Simulation with Same Velocity $0.00142 \mathrm{~m} / \mathrm{S}$.

From the above graph at velocity $0.00142 \mathrm{~m} / \mathrm{sec}$ the pressure drop was changed with respect to time (up to $10 \mathrm{sec}$ ) for different diameter of particles. For small diameter of particles the pressure drop have the positive $\&$ negative and for large diameter particles the pressure drop was almost constant

\section{Conclusions}

When I compared Experimental results with CFD Simulation results I observed that Bed height, Presuuredrop, Voidage profiles with respect to velocity was almost same.in the inverse fluidization the bed height profiles was increased by increasing the velocity after reaching the minimum fluidization velocity, In the pressure drop profiles the pressure was increased up to minimum fluidization was reached after that pressure drop was constantly increased. By changing the diameter of the particles the results was also be changed at low diameter of solid particles the bed height was high when compare to high diameter of particles because the bouncy forces were acting on the upward direction and we have to give the some of forces counter to that upward forces to achieve the fluidization

\section{References}

[1] N. Ulaganathan, K. Krishnaiah, Hydrodynamic characteristics of two-phase inverse fluidized bed, Bioprocesse engineering 15(1996) 159-164@ springer verbiage 1996.

[2] Hee-Dong Han, Won Lee, Young-Kang Kim, Jae-Lee Kwon, HoSuk Choi†, Yong Kang and Sang-Done Kim*, Phase Hold-up and Critical Fluidization Velocity in a Three-Phase Inverse Fluidized Bed, Korean J. Chem. Eng., 20(1), 163-168 (2003).

[3] C. Vijaya Lakshmi, M. Balamurugan, M. Sivakumar T. Newton Samuel, M. Velan, Minimum fluidization velocity and friction factor in a liquid-solid inverse fluidized bed reactor, Bioprocess Engineering 22 (2000) 461 4466 Ó Springer-Verlag 2000.

[4] Fan L. K. Murayama and S. Chern, Hydrodynamic Characteristics of Inverse fluidization in Liquid-Solid and Gas-Liquid-solid Systems, Chemical Engg Journal, 24, 143-150, 1982.

[5] Jena H.M. G.K. Roy, B.C. Meikap. Hydrodynamics of regular particles in a liquid- solid semi-fluidized bed, Powder Technology 196, 246-256, 2009.

[6] McCabe, Smith, and Harriott, book; Unit Operations of Chemical Engineering, 6th edition, McGraw-Hill, 2001.

[7] T. Renganathan and K. Krishnaiah, Stochastic Simulation of Hydrodynamics of a Liquid-Solid Inverse Fluidized Bed, Ind. Eng. Chem. Res. 2004, 43, 4405-4412 4405.

[8] Thiruvengadam Renganathan and Kamatam Krishnaiah, Prediction of Minimum Fluidization Velocity in Two and Three Phase Inverse Fluidized Beds, The Canadian Journal of Chemical Engineering, Volume 81, and June-August 2003.
[9] K.E. Campos-Díaz a**, E.R. Bandala-González b,1, R. Limas-Ballesteros, Fluid bed porosity mathematical model for an inverse fluidized bed bioreactor with particles growing biofilm, Journal of Environmental Management 104 (2012) 62e66.

[10] Jack T. Cornelissena, Fariborz Taghipoura,*, Renaud Escudiéa,b, Naoko Ellisa, John R. Gracea, CFD modeling of a liquid-solid fluidized bed, Chemical Engineering Science 62 (2007) 6334 - 6348. 